\title{
A Clinical Study on Laparoscopic Cholecystectomy in a Tertiary Care Teaching Hospital
}

\author{
Katari Arun', M.Ramu1
}

1. Associate Professor, Department of General Surgery, Prathima Institute of Medical Sciences, Naganoor, Karimnagar.

\begin{abstract}
Address for correspondence: Dr. M Ramu,Associate Professor, Department of General Surgery, Prathima
\end{abstract} Institute of Medical Sciences, Naganoor, Karimnagar.Email: govu941@gmail.com

Submission: 5/1/2021

Review: 27/1/2021

Acceptance: 28/1/2021

DOI:10.47799/pimr.0902.04

\begin{abstract}
Background: Laparoscopic cholecystectomy is gaining popularity for the surgical treatment of gallbladder diseases. The technique has advantages of safe surgery, minimal complications, lower duration of hospital stay, and early return to normal activities. We in the current study tried to evaluate the outcomes of laparoscopic cholecystectomies done in our tertiary care teaching hospital.
\end{abstract}

Methods: Based on the inclusion and exclusion criteria $n=40$ cases were identified and treated with laparoscopic cholecystectomy. A complete history which included the pasthistory, family history, socioeconomic status, nature of symptoms, diet history was obtained. All the patients underwent a complete clinical examination. The investigations carried out were complete blood picture, bleeding time, clotting time, ECG, LFT, KFT, FBS, blood groups, chest $x$-ray, and Ultrasound scan of the abdomen. All cases were operated as per the standard procedures.

Results: The most common sign recorded in the cases was pain in right hypochondrium. Out of $n=40$ cases, $95 \%$ were present with pain $5 \%$ was without pain. Clinical jaundice was found in $10 \%$ of cases and tenderness was found on examination in $95 \%$ of cases. USG showed the presence of multiple stones was in $76 \%$ of cases, thickening of the gall bladder was in $80 \%$ cases and presence of mass was detected in $8 \%$ of cases. The followup period was 3 months in which no complications were reported.

Conclusion: The study found that most of the cases of cholelithiasis now occurring across the spectrum of different ages. The diagnosis has now become easy with the presence of ultrasonography which has sensitivity and specificity. The motto of safe surgery, low morbidity, and early back to work is best done with laparoscopic cholecystectomy.
Keywords: Laparoscopic cholecystectomy, cholelithiasis, gallbladder disease

\section{Introduction}

Susruta is also known as the Father of Indian Surgery has described in his works the description of jaundice called pitta-ashmarijanya meaning jaundice caused due to stone in the bile. ${ }^{[1]}$ other cause of jaundice was due to the wrong diet. Gallstones were first described by the Greek physician Alexander Trallianus who wrote about the calculi within the bile ducts. ${ }^{[2]}$ By the 16th century, both Vesalius and Fallopius described gallstones found in the gall bladder of thedissected human bodies. ${ }^{[2]}$ The prevalence of gallbladder stones varies widely across the world owing to the difference in the preferred diets. In the US at least 20 million have gall stones and that approximately 1 million new cases of cholelithiasis develop each year.Cholelithiasis prevalence in Europe was 18.5\% from the autopsy studies and the lowest prevalence from Ireland5\% and the highest from Sweden38\%. One epidemiological survey in rail and road workers showed that North Indians have a 7 times higher frequency of gall stone as compared with south Indians. ${ }^{[3]}$ The general composition of gallstones mainly includes cholesterol, bilirubin, and calcium salts, with smaller amounts of protein and other materials. ${ }^{[4]}$ Cholesterol is the principal constituent of $75 \%$ of cases of gallstones in western countries. Bacteria in the biliary system release $ß$ glucuronidases, which hydrolyze glucuronic acid from conjugated bilirubin. The resulting unconjugated bilirubin precipitates as its calcium salts. Primary brown pigment stones of the bile ducts often occur in Asians, associated with decreased biliary secretory IgA. ${ }^{[5]}$ About 15 percent of gallstones are calcified enough to be seen on a plain abdominal radiograph, and of these two-thirds are pigment stones. ${ }^{[6]}$ Calcification that is visible only on the rim usually occurs in cholesterol stones. ${ }^{[7]}$ Impaired motility of the 
gallbladder has been cited as another contributing factor in the development of gallstones. Gallbladder stasis associated with high spinal cord injury or with the use of the somatostatin analogue octreotide may provide more convincing examples of stasis as a cause of gallstones. ${ }^{[4]}$ Because of increases in the incidence of gall stones and its variablepresentations in India as well as in the west, there is a great need for a studythat can provide information regarding the prevalence of the disease,various clinical presentations, and management, outcomes of the cholelithiasis.Due to changing lifestyle and health, conscious people arechanging to an unusual diet which has led to the high incidence of cholelithiasis.Medical checkups are now mandatory in corporate recruitment which hasled to the detection of cholelithiasis in the population.

\section{Material and methods}

This cross-sectional study was conducted in the Department of General Surgery, Prathima Institute of Medical Sciences, Naganoor, Karimnagar. Institutional Ethical committee permission was obtained for the study. Written consent was obtained from all the patients involved in the study.

\section{Inclusion criteria}

1. Patients with a diagnosis of cholelithiasis diagnosed with relevant investigations.

2. Those undergoing laparoscopic cholecystectomy

3. Those willing to participate in the study with follow-up examinations

\section{Exclusion criteria}

1. Patients undergoing open cholecystectomy

2. Those with significant comorbidities

\section{Patients not willing to participate in the study}

Based on the inclusion and exclusion criteria $\mathrm{n}=40$ cases were identified and treated with laparoscopic cholecystectomy. A complete history which included the past-history, family history, socioeconomic status, nature of symptoms, diet history was obtained. All the patients underwent a complete clinical examination. The investigations carried out were complete blood picture, bleeding time, clotting time, ECG, LFT, KFT, FBS, blood groups, chest $x$-ray, Ultrasound scan of the abdomen. The patients were kept NBM for 12 hours before the surgical procedure. Preoperative antibiotics were given. A standard laparoscopic surgical procedure was carried out under general anaesthesia. Patient was properly examined in the postoperative period to note the development of any complication. Suitable treatment is given according to the need. Antibiotics were given and subsequently changed according to the bile culture and sensitivity report. Patients were discharged on the third day unless any complication was noted. They were followed up every 15 days for 3 months.

\section{Results}

In this study, the total number of cases was $n=40$ out of which $n=15(37.5 \%)$ were male patients and $n=25(62.5 \%)$ were female cases. The mean age of males in the study was 34.0 years and the youngest patient was male 22 years and the oldest was male 63 years. In the female group, the youngest was 21 years female and the oldest was 62 years female the mean age group of 35.5 years. Most of the cases were from the $31-40$ years age group $n=12(30 \%)$ followed by $n=9(22.5 \%)$ cases of the $21-30$ years and $51-60$ years age group given in table 1.

Table 1: Showing the age-wise distribution of cases in the study

\begin{tabular}{|c|c|c|}
\hline Age in years & Frequency & Percentage \\
\hline $21-30$ & 09 & 22.5 \\
\hline $31-40$ & 12 & 30.0 \\
\hline $41-50$ & 06 & 15.0 \\
\hline $51-60$ & 09 & 22.5 \\
\hline $61-70$ & 04 & 10.0 \\
\hline Total & 40 & 100 \\
\hline
\end{tabular}

The most common sign recorded in the cases was a pain in right hypochondrium. Out of $n=40$ cases, $95 \%$ were present with pain $5 \%$ was without pain. Clinical jaundice was found in
$10 \%$ of cases and tenderness was found on examination in $95 \%$ of cases other details are shown in table 2.

Table 2: signs and symptoms recorded in the cases of the study 


\begin{tabular}{|c|c|c|}
\hline Symptoms/signs & Frequency & Percentage \\
\hline Pain in right hypochondrium & 38 & 95.0 \\
\hline Nausea/ vomiting & 23 & 57.5 \\
\hline Jaundice & 4 & 10.0 \\
\hline Dyspepsia & 6 & 15.0 \\
\hline Fever & 4 & 10.0 \\
\hline Tenderness & 38 & 95.0 \\
\hline Guarding & 8 & 20.0 \\
\hline Mass & 0 & 0.0 \\
\hline
\end{tabular}

Apart from the other investigations, the USG abdomen was done for all the patients. Thediagnosis confirmed by USG was $100 \%$ for cholelithiasis. Apart from other findings presence of multiple stones was in $76 \%$ of cases, thickening of the gall

\begin{tabular}{|c|c|c|}
\hline USG Findings & Frequency & Percentage \\
\hline Stones in the gall bladder & 40 & 100 \\
\hline Solitary stone & 6 & 15.0 \\
\hline Multiple stones & 29 & 72.5 \\
\hline Bile duct stones & 0 & 25.0 \\
\hline Thickening of gall bladder & 10 & 7.5 \\
\hline Dilated bile duct & 3 & 0 \\
\hline Mass & 0 & 0.0 \\
\hline
\end{tabular}

The examination of gall stones revealed $80 \%$ mixed type cholesterol stones in $15 \%$ and pigmented stones in $5 \%$ of cases. The histopathology reports revealed $n=38$ patients were reported has had chronic cholecystitis, $n=2$ patients had acute cholecystitis and no case of malignancy was noted. In almost all the cases the postoperative period was uneventful. $5 \%$ of cases were reported with vomiting which was managed with antiemetic agents. $15 \%$ had severe pain which was managed adequately with analgesics. The follow-up period was 3 months in which no complications were reported.

\section{Discussion}

Laparoscopic cholecystectomy is a minimally invasive surgical procedure for the treatment of diseased gallbladder. This technique is now gaining popularity compared to the open technique since the early $1990 .{ }^{[8]}$ Laparoscopic cholecystectomy is indicated for the treatment of cholelithiasis, acute or chronic cholecystitis, gallstone pancreatitis, gallbladder masses, or polyps. ${ }^{[9]}$ These indications are the same bladder was in $80 \%$ cases and presence of mass was detected in $8 \%$ cases of the study shown in table 3.

Table 3: Showing the Ultrasonographic findings of cases of the study

for an open cholecystectomy. However, Cases of gallbladder cancers are usually best treated with open cholecystectomy. Studies have shown that laparoscopic cholecystectomy has several advantages as compared to open cholecystectomy which includes lower rates of complication, shorter duration of hospital stay, and lower mortality. ${ }^{[10]}$ Apart from these, better cosmetic results are owing to small wounds and scars, early return to daily activities, and preferred in older patients with comorbid conditions. $\left.{ }^{[11-13}\right]$ In the present study we observed $n=15(37.5 \%)$ were male patients and $n=25(62.5 \%)$ were female cases. Other studies in this field have also reported similar female preponderance in the cases. ${ }^{[14-17]}$ In the current study we found $n=19$ cases with acute onset of pain while others were found with chronic or relapsing pain similar results were observed by A Sharma ${ }^{[16]}$ andGaney et al; ${ }^{[17]}$. The common site of pain was the right hypochondrium and epigastric. $5 \%$ of cases complained of radiation of pain to back. $15 \%$ complained of colicky pain and the rest had dull aching pain. Similar presentations were noted in Goswitz et al; ${ }^{[18]} 57.5 \%$ 
had nausea and vomiting in our study. The vomiting was spontaneous and, in most cases, occurred following the onset of pain.Ganey et al; series ${ }^{[17]}$ Incidence of fever was found in $10 \%$ of cases was secondary to cholangitis due to biliary obstruction. Ultrasound scanning revealed gall bladder stones in $100 \%$ of cases and solitary stones were found in $15 \%$ of cases and $72.5 \%$ of cases had multiple stones. The examination of gall stones revealed $80 \%$ mixed type cholesterol stones in $15 \%$ and pigmented stones in $5 \%$ of cases. The histopathology reports revealed $n=38$ patients were reported has had chronic cholecystitis, $n=2$ patients had acute cholecystitis and no case of malignancy was noted.Postoperative minor complications were noted which were managed adequately and no major complications were noted in 3 months follow-up.

\section{Conclusion}

The study found that most of the cases of cholelithiasis now occurring across the spectrum of different ages. The diagnosis has now become easy with the presence of ultrasonography which has sensitivity and specificity. The moto of safe surgery, low morbidity, and early back to work is best done with laparoscopic cholecystectomy. All the cases amenable for laparoscopic cholecystectomy must be done wherever feasible.

\section{REFERENCES}

1. K Park. Man and medicine towards health for all. Park's Textbook of preventive and social medicine, K Park, Banarasi Das Publishers. 17th edition Nov 2002, 1-10.

2. BlumgartLH.Y Fong Editors. Gallstones and gallbladder.Textbook of Surgery of liverand biliary tract,Harcourt Publishers 2002; Vol 1:617-791.

3. Rakesh Tendon, Siddharth N Shah. Diseases of the gallbladder and biliary tract. API Text ofmedicine,7th edition, 2003;642-644.

4. David.E., Johnston Marshall.M.Kaplan.Pathogenesis and treatmentof gallstones. The new England journal of medicine. 1997;6(328):412-421.

5. Yio XY, Jin BW, Yin FZ, Li XJ. Bile secretory immunoglobulin $A$ in biliaryinfection and cholelithiasis. Gastroenterology 1992;102: 1000-08.

6. Trotman BW, Petrella EJ, Soloway RD, Sanchez HM, Morris TA III, MillerWT. Evaluation of radiographic lucency or opaqueness of gallstones as ameans of identifying cholesterol or pigment stones: correlation of lucency oropaqueness with calcium and mineral.Gastroenterology $1975 ; 68: 1563-66$.

7. Dolgin SM, Schwartz JS, Kressel HY, et al. Identification of patients with cholesterol or pigment gallstones by discriminant analysis of radiographicfeatures. N Engl J Med 1981; 304:808-11.

8. Kapoor T, Wrenn SM, Callas PW, Abu-Jaish W. Cost Analysis and Supply Utilization of Laparoscopic Cholecystectomy. Minim Invasive Surg. 2018; 7838103.

9. Strasberg SM. Tokyo Guidelines for the Diagnosis of Acute Cholecystitis. J Am Coll Surg. 2018;227(6):624.

10. Blythe J, Herrmann E, Faust D, Falk S, Edwards-Lehr T, Stockhausen F, Hanisch E, Buia A. Acute cholecystitis - a cohort study in a real-world clinical setting (REWO study, NCT02796443). Pragmat Obes Res. 2018;9:69-75.

11. Kose SH, Grice K, Orsi WD, Ballal M, Coolen JML. Metagenomics of pigmented and cholesterol gallstones: the putative role of bacteria. Sci Rep. $2018 \mathrm{Jul}$ 25;8(1):11218.

12. Sarawagi R, Sundar S, Raghuvanshi S, Gupta SK, Jayaraman G. Common and Uncommon Anatomical Variants of Intrahepatic Bile Ducts in Magnetic Resonance Cholangiopancreatography and its Clinical Implication. Pol J Radiol. 2016;81:250-5.

13. Sherwinter DA. Identification of anomalous biliary anatomy using near-infrared cholangiography. J Gastrointest Surg. 2012 Sep;16(9):1814-5.

14. Battacharya R. Cholecystectomy in west port, New Zealand. Indian journal of surgery, August 1983; 450-455.

15. AP Tamahankar. The fate of gall stones: Traditional practice questioned. Ann RCollSurgEngl 2003; 85: 102104.

16. Maj. Alok Sharma. Towards a safer cholecystectomy - the fundus to porta approach. Indian journal of surgery. 1997; 141-145.

17. Ganey J B. Cholecystectomy: Clinical experience with a large series. Am J Surg 1986; 352-357.

18. Goswitz J T. Bacteria and biliary tract disease. Am J Surg. 1974; $128: 644$.

How to cite this article : Katari A,Ramu M. A Clinical Study on Laparoscopic Cholecystectomy in a Tertiary Care Teaching Hospital. Perspectives in Medical Research 2021; 9 (2):15-18 DOI:10.47799/pimr.0902.04

Sources of Support: Nil, Conflict of interest: None declared 